Session 5-2

\title{
Simulating the Engineering Workplace: An Innovative Teaching Methodology in a Senior Electrical Engineering Class
}

\author{
Carol Costello, August Allo \\ Department of Electrical and Computer Engineering \\ University of Texas at San Antonio
}

\begin{abstract}
Concerns regarding the ability of the U. S. to produce competitive scientists and engineers have stimulated a major reconsideration of curricula in many universities. This paper documents the results of an innovative engineering professionalism program integrated into the first semester of a two-semester Electrical Engineering senior-level capstone design class required for graduation from the University of Texas at San Antonio (UTSA). Evolved over a period of several semesters as a recitation enhancement to the course, these workshops complement the engineering professionalism, business, and project management aspects of the engineering design class with scientific writing, professional oral presentations and teamwork / interpersonal skills to simulate the engineering workplace. The positive impact of the series of 12 weeks of classroom work and individual counseling has been documented by significant improvements in confidence recorded by the students themselves on entry and exit selfevaluations questionnaires and by the increase in professionalism of the assigned engineering documents and presentations delivered to the class, which have risen to the level of industry quality. As UTSA is the third largest Hispanic-serving institution in the U. S., the results are further underscored by the fact that $42 \%$ of the design students are classified as ESL (English as a second language); 34\% of the class is bilingual SpanishEnglish. Methodology of motivating minorities is discussed.
\end{abstract}

\section{Introduction}

In an effort to continuously improve the quality of education, the Electrical and Computer Engineering Department (ECE) has made revisions to the curriculum for the capstone design courses required of all senior year ECE majors, which is a two semester course of study, Design I \& II. These courses are geared to simulate the experience of engineers in an industrial setting while maintaining an entrepreneurial atmosphere.

The curriculum for the Design courses covers the progression from design conception to the creation of working prototypes. The program addresses the need for professional quality enhancement of communication skills consisting of scientific writing, presentations, and interpersonal skills, including working in teams. The classes

Proceedings of the 2008 ASEE Gulf-Southwest Annual Conference

The University of New Mexico - Albuquerque

Copyright (C) 2008, American Society for Engineering Education 
preceding the design class do not focus on simulating an environment that would involve the documentation or oral skills required by the workplace; therefore, it was decided that to optimally prepare the graduates to excel in their ability to express their ideas in writing or orally to a variety of audiences, a recitation program would be created within the capstone design course curriculum.

The results of the integration of the recitation curriculum have been analyzed via student self-evaluation questionnaires at the beginning and at the end of the semester and the evaluation of students' assignments and presentations for professional quality. Dramatic improvement in self confidence and communication abilities has been documented in written and oral work assignments. In addition, techniques to manage awareness of interpersonal relations were briefly covered ${ }^{1}$. This paper provides details of the program and the most salient results. The sub-group of English as Second Language (ESL) and international students received special attention and instruction in composition and presentation skills. UTSA is the third leading institution of Hispanic graduates in the nation.

\section{Methodology}

The content of the series of recitation lectures evolved over a period of two semesters. Measures of student reaction to the recitation workshops included recording the average number of attendees in classes; attendance was voluntary for most of the lectures. In addition, the authors spent many hours interviewing a variety of students from the classes in order to determine perceptions of the students concerning the need for and utility of various topics covered in the recitation. The authors administered an entry survey to obtain self-evaluation information and perception of needs at the beginning of the semester (the end of August). An exit survey was administered in order to compare the opinions of the students before and after the 12 week period (ending in late November) and to request specific information as to what had been useful; attachments 1 and 2 contain the two surveys. Ratings on a scale of five and written comments concerning the recitation portion of the class are reflected throughout this paper.

During the preceding two semesters, in order to determine an optimally effective agenda for the writing-oriented recitation lectures, the authors tried a number of traditional methodologies and found that the following were less than effective in teaching professional and scientific writing techniques to senior level engineering students:

- Teaching grammar in class

- Using “group proofreading” methods by masking mistakes made by the class, and asking them to discover and correct them

- Providing detailed grammatical notes on students' assignments

- Treating ESL no differently than native English speakers

- Not practicing the content of the lecture in class

- Failing to explain the partnership and common goals between the teacher and students

Proceedings of the 2008 ASEE Gulf-Southwest Annual Conference

The University of New Mexico - Albuquerque

Copyright (C) 2008, American Society for Engineering Education 
In August 2007, a new recitation syllabus containing a fixed series of treatments, based on the experiences of the Fall and Spring semesters of 2006, was introduced. Sufficient flexibility was provided in the syllabus to integrate writing or presentation educational units as needed and indicated by the Entry Survey, administered the first class.

To the extent possible, the recitation portion of the class, one hour per week following the engineering lecture, was tied closely to the engineering content. For example, the first assignment requiring a patent and literature search was followed with a lecture and practice on IEEE (Institute of Electrical and Electronics Engineers) writing, citation and reference standards and a group analysis of an engineering publication highlighting the characteristics of formal writing skills. After the assignment was submitted and evaluated, feedback was provided to the students in general, beginning always by praising them for what was done well (“catch 'em doing something right”), and then underscoring or questioning problem areas. Separate grades on assignments were given on the technical content and composition quality, reflecting how close the assignment was to industry quality.

Both authors read all documents, and were in accord on the composition rubric assigned. C. Costello approached students in class or personally invited them for office visits to discuss some of the specifics of the problems. The approach taken was validating the difficulties inherent in writing engineering documents, and that the talent and intelligence of the student could be masked by writing problems. Working with the students, ways of "unmasking" the clarity of thoughts and explanations were discovered by leading them to a solution, but allowing the student to express it ("garden path" technique). It is important to note that the availability of professional resume advice was presented in class, and then followed up on in private sessions with many of the students. This served to make them aware of how important composition skills are in the workplace, and the importance of writing to a professional and non-professional engineering audience. Awareness gained by resume work carried over into the engineering writing assignments.

Presentation skills were approached in a two-stage method. First, the factor of the natural fear of public speaking was examined, and then the students were provided with a template for the presentations expected for their mid-term and final oral performance. A rubric, also made available to the students early in the semester, was used for the formal evaluation.

The initial number of 35 students was reduced to 32 due to withdrawals from the class. A record was kept for most classes to reflect class attendance, which averaged 25 students.

\section{Results}

The practical application of the abilities to write and present as related to the leadership qualities sought by industry was emphasized in most of the lectures. The nine documents assigned were similar to documentation expected in the engineering workplace. The

Proceedings of the 2008 ASEE Gulf-Southwest Annual Conference

The University of New Mexico - Albuquerque

Copyright (C) 2008, American Society for Engineering Education 
competitive edge of good writers and speakers in obtaining choice assignments in a company setting, or communicating with potential investors as an entrepreneur, was exemplified in the templates for written work and presentations. In addition, teamwork and open lines of communication were "lived" in the team effort required to demonstrate how it can "make or break" professional success.

Writing Skills

When asked in the entry survey what the students would like to improve about their writing, the following was mentioned:

- Want to translate my ideas to paper

- Convert technical information into readable form, making it easier to understand, avoid being so dry and boring

- Be sure to be complete and correct, avoid repetition

- Remove emotion from statements

- Be able to communicate to different audiences

- Learn techniques on writing with others as a team

- How to organize material

- How to iron out problems with grammar

- How to avoid usage of personal pronouns (I, me, we)

- How to catch typos, spelling

- Learn the mechanics of scientific writing (citations, sources, bibliography, description of illustrations, figures and tables)

- Abstracts, introductions and conclusions are difficult to compose

The objective discussed with the class was the incremental improvement of writing by moving from an average or below average rating up to industrial quality of excellence or solid above-average quality. It was made clear that improvement is a process, and that the individuals needed to be aware of incremental progress from one assignment to another. Feedback came in the form of individual notes on the assignments (not specific, as we had the impression that the students did not read or understand specific corrections such as grammatical points or explanations), and to the class as a whole on general areas of difficulty. Students were encouraged to visit the PIs privately for specific feedback and ideas. The students were reminded that the comments on their writing were not aimed at them personally, but that it was better to know what areas were problematic in this business simulation, rather than finding out later on the job, where faulty writing skills can be disadvantageous.

The titles for the lectures were important as attendance was voluntary, followed one hour of "hard" engineering content, and communication skills have the reputation of being "soft” skills, which minimizes importance.

Several of the lecture titles are carefully devised to attract attention, and exemplary of a "user-friendly" approach to writing:

- Why Scientific and Engineering Writing is Different: A Short History of the English Language

Proceedings of the 2008 ASEE Gulf-Southwest Annual Conference

The University of New Mexico - Albuquerque

Copyright (C) 2008, American Society for Engineering Education 
- Ten Quick Tips for Success in Writing Engineering Documents

- Blasting Ten Writing Myths

- Writing the Most Important Document in Your Life: Your Resume

The most common problems encountered in the students' written work were:

- Need to upgrade informal words and expressions to Latin-based, more formal scientific renderings

- Depersonalizing the writing by minimizing use of "our team," and personal pronouns

- Superfluous verbiage

- Trust in spell check as the final arbiter of correct orthography

- Formatting and citation irregularities

As an added incentive, the students were offered the opportunity to perform a voluntary re-writing of assignments for additional credit.

In tracking the quality of the written assignments, all groups showed incremental improvement after two or three of the eight assignments, most receiving consistently an outstanding or above average rating.

\section{Writing progress}

Composition Skills Self-Evaluation EE 4811

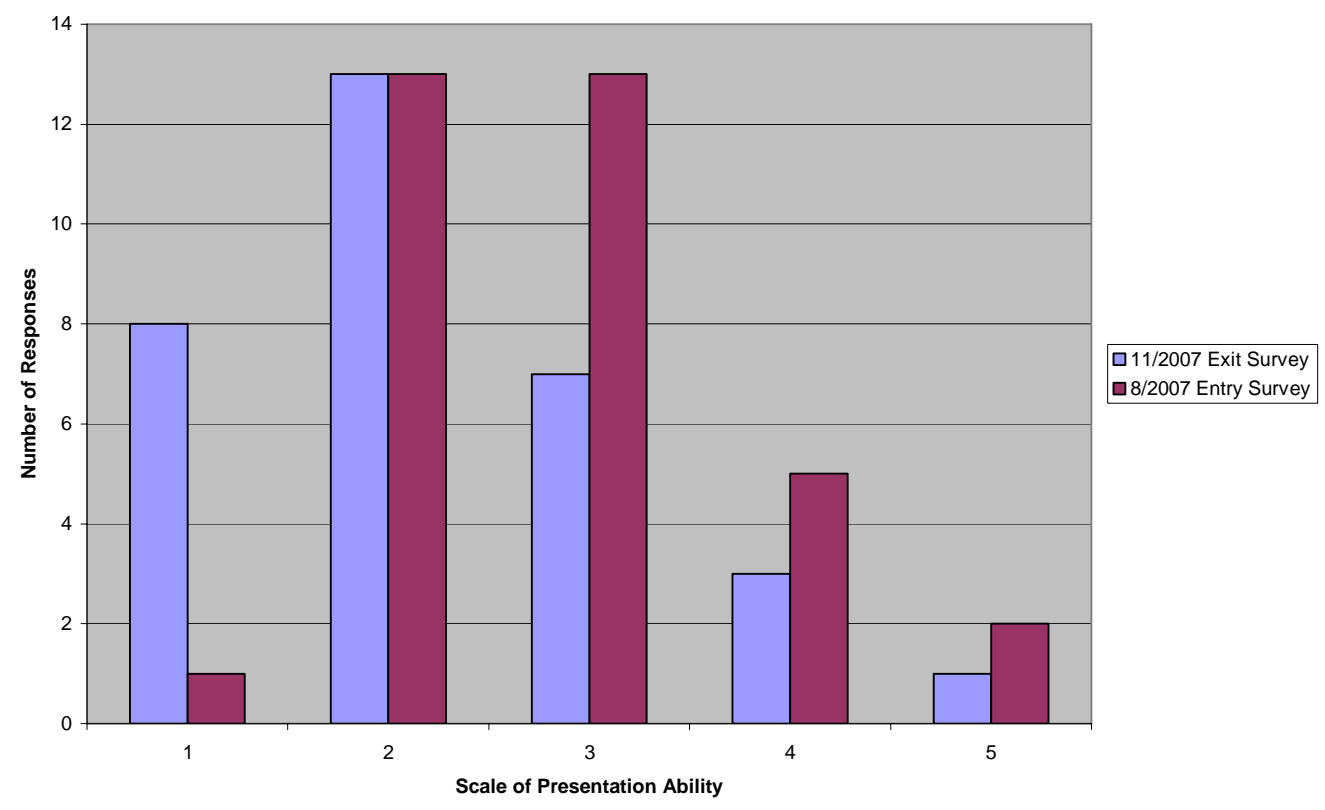

Figure One: Progress in Self-Evaluation of Writing Skills over a three month period

Scale: 1 = Outstanding $2=$ Pretty Good 3 = Average 4 = Could Improve $5=$ Need practice 
In the Exit survey, 21 or $66 \%$ of the class rated themselves above average or better in comparison to 14 or $40 \%$ of the class who categorized themselves thus at the beginning of the semester. Even those who felt themselves possessing only average or below skills moved up incrementally; at the end of the semester only 11 (34\%) of the students placed themselves in this category, while at the beginning of the semester, 19 (54\%) did.

When asked if anything they had learned in class helped with their writing skills, the most frequent comments were:

- Improvement in vocabulary, more scientific vocabulary

- Fewer grammatical errors

- Learned to minimize personal references in documents

- Making a document more interesting to read

- Writing for different audiences

- Using less verbiage, writing became concise and to the point

- The guidelines and formatting examples helped, along with the assignment structures provided

Several students commented that they would like to have had more grammar taught in class!

Writing for English as a Second Language (ESL) Students

ESL students constitute $42 \%$ of the class (ESL typically varies between 30 to $45 \%$ of the class). Persian, Ibo (a Nigerian dialect), and Chinese were spoken by four students. Spanish was the first language of $34 \%$ of the class. During the assignment of the first writing task, an announcement was made concerning special standards for ESL students. ESL students would be held to the same high standards as the rest of the class, but extra help for assignments would be available. The rest of the class agreed to this publicly announced decision when it was pointed out that when asked to work in a country where another language was used, they would also wish to have help in a language which is not their mother tongue. It was also pointed out that poor writing skills will hamper the advancement and opportunities of English as a first language employees and ESL employees alike ${ }^{2}$.

Several techniques were used to assist ESL students. Some were personally tutored by C. Costello. Others were approached as they received their assignments and grades, and praised for their expression in English. The differences between English and Spanish were pointed out, as the influence of mother tongue in a second language is a well known phenomenon. To facilitate English expression, simplification of sentence structure (syntax) was practiced with comparison to Spanish translations, noting that the Romance tongues generally require more text compared to English. In many cases, the ESL students had the tendency to use colloquial language regarding Engineering, rather than a more formal level of expression. In one technique used to focus on scientific expression, ESL Spanish speakers were asked to translate colloquial English expressions into Spanish (eg. get, think) and then identify an English cognate which "elevates" the expression (get $=$ obtener $=$ obtain, think $=$ considerar $=$ consider $)^{3,4}$. In addition, a list of scientific 
alternative terms developed by the instructors proved useful to these students ${ }^{5}$. In many cases linguistic work enhanced not only the quality of the written work, but the overall confidence of the students, especially those who realized that Spanish as a first language can be an advantage in scientific writing.

Comments from the Spanish ESL students on the writing portion of the class were:

- Got a lot of help on abstracts for the honors college

- Help and support for international students was available

- Learned better vocabulary usage

- Improved formal writing skills

- Instructors were available for help with writing assignments

First language was not determined in the entry survey; thus, results of the ESL subgroup could not be compared with precision to exit survey comments. ESL identification will be added to future entry surveys.

\section{Presentation Skills}

Three presentations were required for the Design I class. Following the units focusing on writing, an "Icebreaker" of less than one minute was requested as an introduction of each student and their interests to the rest of the class. The next presentation was a fiveminute PowerPoint team effort to introduce their design ideas. The last presentation was a formal 10 to 14 minute proposal presentation containing a project plan through the end of the next semester. This latter was the only presentation on which the team was graded using a rubric. In addition, individual "score cards" were given to team members immediately after their presentation on what they had done well, and on areas for improvement ${ }^{6}$.

The Entry Survey showed that "nervousness" was cited most frequently in relation to presentations. The details the students included on their survey included the following manifestations of anxiety:

- Feeling of excitement with sweaty palms

- Shaky voice, talking too fast

- Trouble making eye contact

- What to do with my hands

- Pacing

- Fear of large groups

Other difficulties mentioned:

- Blockage in thought, leaving out material

- Pacing of the presentation

- How to deal with questions

- Use of "um" and "ah" as fillers

- Need for better vocabulary 
Other comments concerned organization and esthetics of the slides.

ESL students volunteered that they felt they were at a disadvantage with accent, pronunciation and vocabulary.

In order to deal with the fear of public speaking, a lecture validating the biological manifestation of fear and how to manage the fear was presented to the class. The lecture dealt with attitudes projected upon the audience, and encouraged the students to see the classroom as a safe forum for experimenting with presenting. Each student then made the "icebreaker" introductory presentation.

During the next lecture, more details and examples of making a PowerPoint were given along with a team who had volunteered to do a model presentation as a template for the rest of the class. The construction of the presentation was analyzed by one of the authors and the class, and the next week the rest of the groups presented.

The last formal presentation occurred about one month later during the last class session for the semester and received both personal feedback (in the form of "scorecards") and rubric based team ratings.

Presentation Skills Progress

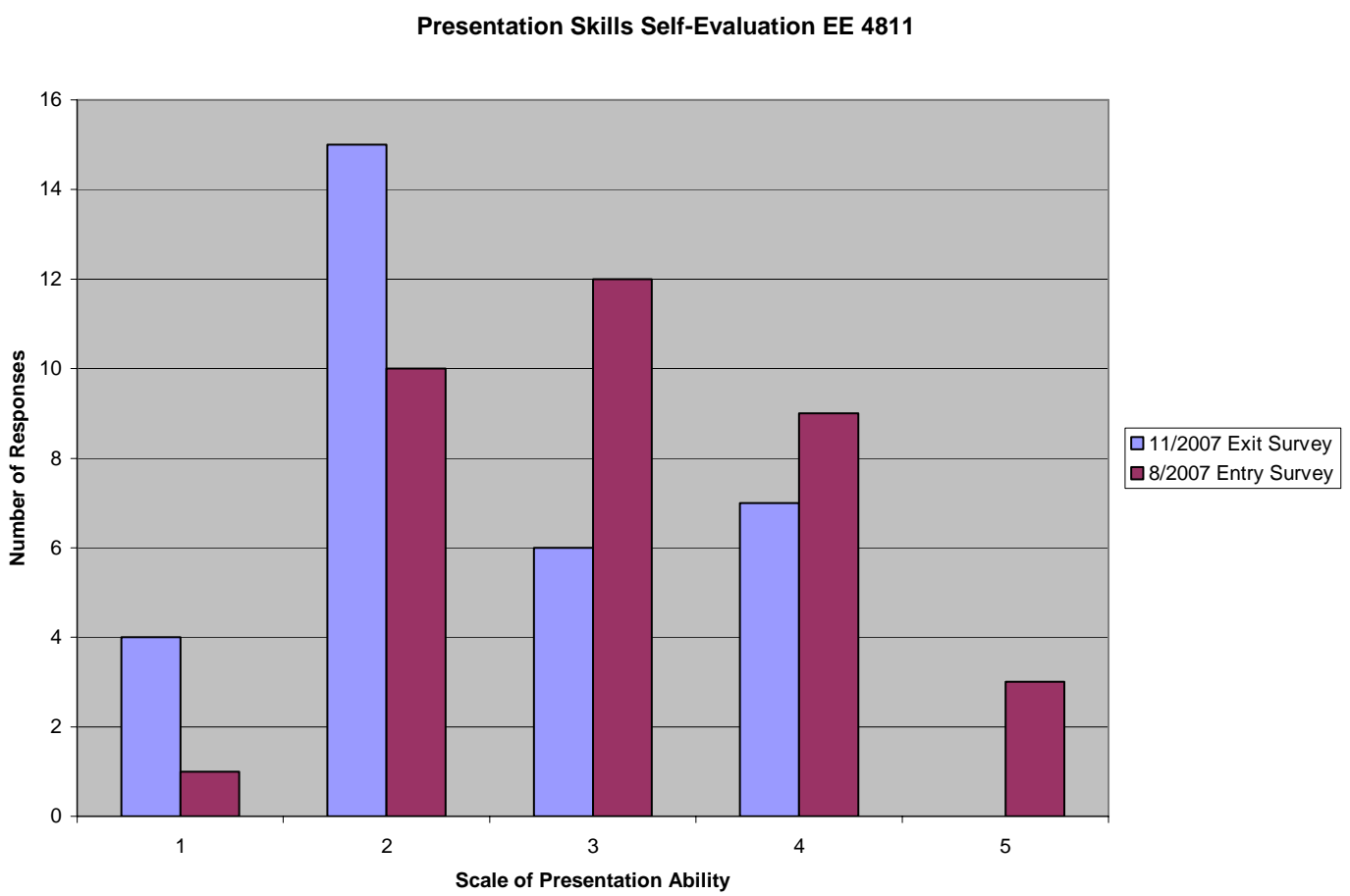

Figure Two: Progress in Presentation Skills over a three-month period

$1=$ Outstanding $2=$ Pretty Good 3 = Average 4 = Could Improve $5=$ Need practice 
In the Exit survey concerning self-evaluation of presentation skills, 19 (59\%) of the students rated themselves as outstanding or above-average presenters, almost twice the number 11 (31\%) who had rated themselves that highly in the Entry survey. However, $41 \%$ of the class still rated their skills as average or below. This is, however, a notable reduction compared to the 24 (67\%) who rated their skills average or below three months earlier. Despite the improvements seen, 10 (31\%) of the class asked for more practice. Additional voluntary presentation practice sessions during the laboratory portion of the class are planned for future semesters.

In response to the question as to whether the class helped with presentation skills, many of the replies denoted increased self-confidence through learning:

- How to keep audience attention, engaging the audience

- Recommendation of Toastmaster's Organization for increased practice

- How to maintain eye contact

- Importance of preparation

- Awareness of how I present

- Overcome fear of public speaking

- Timing and organization of presentation

- Body language

- Visual aids--how to make colorful and attractive presentations

- Immediate feedback after presenting

- Appealing to different kinds of audiences

\section{ESL Presentation Skills}

By mid semester, when the ESL students had practiced their written expression and received personal counseling, many seemed more at ease in the class. Several groups asked to have their presentations checked before they were given publicly. Confirmation that slower, clear speech was acceptable in public speaking and having a distinctive accent as an advantage were apparently motivational to these students.

Interpersonal Skills

When asked in the Entry Survey if interpersonal skills and techniques were important, almost all of the students indicated they were interested, especially from the point of view of teamwork. When further queried as to what they wanted to learn to enhance relations with others, they mentioned:

- Facilitate boss-employee relationship

- Become less introverted

- Learn managerial and leadership skills

- How to get work done through people

- Dealing with female to female and male-female in workplace

- Learn skill levels of others

- How to motivate people

- How to make a good first impression

- How to act as a mediator

Proceedings of the 2008 ASEE Gulf-Southwest Annual Conference

The University of New Mexico - Albuquerque

Copyright (C) 2008, American Society for Engineering Education 
- How to be more open when problems occur

- Remain diplomatic under pressure

- Handle differences in opinions

- Dealing with bossy people

One class session consisting of a short test to determine one's own personality style was followed by an analysis of the four basic personality types, and how to deal with them. Well known personalities were used to exemplify the characteristics, both positive and negative, of each type. Comments from the students on the Exit Survey included:

- Helped to learn what kind of person I am

- Feel more comfortable with others

- Understand others better

- Fun and informative analysis

- Helps identify with group members

- Techniques of handling other work

- A real-world skill

- Learned how to package communication for personality types

Twenty-four (75\%) of the class found the material on handling people useful and several asked that more time be devoted to the subject with explanation or role-play integrated.

\section{Summary and Conclusions}

In summary, a description of the methodology used to enhance communication skills in ECE at UTSA was presented along with a detailed analysis of the impact on students' communications skills as well as the students' perception thereof. The communication skills progress demonstrated by this intensive, student-focused series of recitation lectures was clearly superior to classes taught in previous semesters. Both the English mother tongue and ESL speakers advanced successfully through the incrementally demanding writing assignments; the majority of the class was rated at industry level by the end of the semester. This improvement carried over into superior, industry-quality presentations and improved teamwork on their assignments. Overall self-confidence during the three month period underscored the gains in communication skills made by the students.

\section{References}

1. Ivins, J. R., “Interdisciplinary Project Work: Practice Makes Perfect?" IEEE Transactions on Education, Vol. 40, No. 3, pp. 179-183, 1997.

2. Lax, J., "The Effect of a Timed Writing Assessment on ESL Undergraduate Engineering Students." 2005 IEEE International Professional Communication Conference Proceedings, pp. 40-46. 
3. Hamers, J. F., Blanc, M. A. H., Bilinguality and Bilingualism. Cambridge: Cambridge University Press, 1989.

4. Nagy, W. E., Garcia, G. E., Durgunoglu, A., Hacin-Bhatt, B., “Spanish-English Bilingual Students’ Use of Cognates in English Reading,” Bilingual Research Journal, Vol. 18, pp. 83-97, 1993.

5. Mudraya, O., "Engineering English: A Lexical Frequency Instructional Model,” English for Specific Purposes, Vol. 25, No. 2, pp. 235-256, 2006.

6. Rose, A. T., "Improving Student Skills in Multimedia Presentations," $32^{\text {nd }}$ ASEE/IEEE Frontiers in Education Conference, Boston, MA, November 6-9, 2002.

AUGUST J. ALLO, JR.

August Allo currently serves as a Lecturer in the Department of Electrical and Computer Engineering at The University of Texas at San Antonio. His background includes industry experience in medical device development and testing. His interests include engineering education, Energy Harvesting, MEMS/NEMS, MEMS/NEMS Sensors, Bio-MEMS/NEMS, and Biomedical Signal Processing.

\section{CAROL A. COSTELLO}

Carol Costello currently serves as a Communications Specialist with the Department of Electrical and Computer Engineering at The University of Texas at San Antonio. Her research interests include scientific communications and linguistics, specializing in bilingual-bicultural issues in an engineering classroom setting. Her background encompasses international industry in the marketing-manufacturing area, and multi-lingualism. 


\section{Attachment 1}

Name (optional)

Use the back of this paper if you don’t have sufficient space to write your comments.

Scale:

$1=$ Outstanding $2=$ Pretty Good $3=$ Average $\quad 4=$ Could Improve $5=$ Need practice

1. How do you rate your presentation skills?

Why? Be specific about what you would like to work on to upgrade your skills

2. How do you rate your written skills for engineering documents?

Have you written scientific papers before?

If so, what kind?

What is most difficult in writing an engineering report?

3. Interpersonal skills are important in all parts of life, especially in teamwork. How much do you feel you know about figuring out what makes other people "tick"? Is this important to you?

Is there anything specific you want to learn about better relationships with co-workers, team mates, etc.? Please be specific.

4. How interested are you in learning about the following?

Effective resumes

Practicing the job interview

Other suggestions for topics concerning communication to help you be more professional on the job.

Proceedings of the 2008 ASEE Gulf-Southwest Annual Conference

The University of New Mexico - Albuquerque

Copyright (C) 2008, American Society for Engineering Education 


\section{Attachment 2}

Name (optional)

E-Mail(Optional)

We follow up with selected students as they proceed into the Design II class and careers for information and publicity purposes. If you do not mind being contacted, please provide your email address.

Use the back of this paper for sufficient space to write your comments.

Scale:

$1=$ Outstanding $2=$ Pretty Good $3=$ Average $4=$ Could Improve $5=$ Need practice

4. How do you currently rate your presentation skills?

Have you learned anything in this class that has helped you? If so, what?

In your opinion, should the classes on presentation skills be modified? If so, how?

5. How do you currently rate your written skills for engineering documents?

Have you learned anything in this class that has helped you? If so, what?

In your opinion, should the classes on writing skills be modified? If so, how?

Is there any additional information on writing which you think would be helpful?

6. We briefly covered interpersonal skills and detecting different personality types. Was this material helpful to you? If so, why? If not, why not?

Is there anything in your opinion that we should change to make this material more effective?

4. Were there any other communications-related services (resume, cover letters, applications) that you took advantage of in or out of class? If so, what, and how was it helpful?

5. Please provide other suggestions for topics concerning communication to help you be more professional in your career or in graduate school. What information should be added to the communications classes to make them more effective?

6. What is your first language(s)?

Second Language?

Do you have any suggestions for accommodation or help in this class if English is not your first language?

Proceedings of the 2008 ASEE Gulf-Southwest Annual Conference

The University of New Mexico - Albuquerque

Copyright (C) 2008, American Society for Engineering Education 